\title{
The Combination Therapy with Bromocriptine and Cyproheptadine in Patients with Acromegaly
}

\author{
Kunihiko Hanew, Akira SUGAWARA, Yasuyuki ShimizU, Shuichi SATO, \\ Atsushi SASAKI, SATORu TAZAWA*, Kiyoshi ISHII* Tsuyoshi SAITOH**, \\ SHUNICHI SASO** AND KaORU YOSHINAGA
}

\author{
The Second Department of Internal Medicine and Department of Radiology*, \\ Tohoku University School of Medicine, Sendai 980, and Miyagi \\ National Hospital**, Yamamoto-cho 989-22, Japan
}

\begin{abstract}
The therapeutic efficacy of the combination of cyproheptadine and bromocriptine was studied in 15 patients with active acromegaly showing incomplete GH suppression in response to bromocriptine therapy alone. The mean basal plasma $\mathrm{GH}$ was $31.3 \pm 5.5 \mu \mathrm{g} / \mathrm{L}$, and it decreased to $19.0 \pm 3.9 \mu \mathrm{g} / \mathrm{L}$ during the single bromocriptine therapy ( 10 to $20 \mathrm{mg}$ for 2 to 21 months). When cyproheptadine (12 to $16 \mathrm{mg}$ for 8 to 52 months) was added to bromocriptine therapy, plasma GH decreased further $(9.4 \pm 3.0 \mu \mathrm{g} / \mathrm{L}$ : vs pretreatment, $\mathrm{P}<$ 0.001 ; vs bromcriptine treatment, $\mathrm{P}<0.005)$, and $\mathrm{GH}$ normalization was obtained in 8 patients. The plasma somatomedin-C levels in these 8 patients $(0.3-1.8 \mathrm{U} / \mathrm{ml})$ were within the normal range during the combination therapy. Plasma GH responses to TRH or GHRH were markedly suppressed in 6 patients during the combination therapy compared to pretreatment or during bromocriptine treatment. In addition, a clear reduction in the tumor size was observed in 4 of 7 previously untreated patients during the combination therapy. In conclusion, cyproheptadine has therapeutic efficacy in acromegalic patients who showed incomplete $\mathrm{GH}$ suppression in response to treatment with bromocriptine alone. Following the cyproheptadine and bromocriptine combination therapy tumor shrinkage was observed in some patients.
\end{abstract}

As a medical treatment for acromegaly, bromocriptine has been widely used (Daughaday, 1985 ; Frohman, 1987).

With this treatement, however, normalization of plasma $\mathrm{GH}$ is obtained in only about $20 \%$ of cases (Faglia et al., 1985). We have already reported that dopaminergic agents, which can cross the blood brain barrier, might have a dual action on $\mathrm{GH}$

Received March 3, 1989 secretion in acromegalic patients; one is a direct somatotroph inhibition and another is a indirect somatotroph stimulation via the CNS (Hanew et al., 1987). Therefore, it seems likely that bromocriptine therapy is not effective in acromegalic patients whose hypothalamic GHRH secretions are stimulated by bromocriptine.

In such cases, the combination of hypothalamic GH suppressants with bromocriptine might be desirable (Hanew et al., 1987). 
Cyproheptadine is known to suppress $\mathrm{GH}$ secretion in normal and some acromegalic patients (Bivens et al., 1973; Nakai et al., 1974; Smyth and Lazarus, 1974; Nakai et al., 1975; Chihara et al., 1976; Feldman et al., 1976; Dammacco et al., 1977 ; Hainer et al., 1981; Kato et al., 1983), probably through the central antiserotonergic actions (Bivens et al., 1973; Nakai et al., 1974; Smyth and Lazarus, 1974 ; Chihara et al., 1976; Feldmen et al., 1976 ; Dammacco et al., 1977).

In this study, we have examined the therapeutic efficacy of the cyproheptadine and bromocriptine combination therapy in 15 patients with active acromegaly who did not show GH normalization in response to treatment with bromocriptine alone.

\section{Materials and Methods}

Fifteen patients with active acromegaly (8 males and 7 females, aged 23 to $73 \mathrm{yr}$ ) were studied (Table 1). These patients had increased plasma GH (8.7-73.4 $\mu \mathrm{g} / \mathrm{L} ;$ normal range $<6 \mu \mathrm{g} /$
L), enlarged sella turcica by plain XP, pituitary adenomas by CT scan, and other clinical manifestations of $\mathrm{GH}$ excess. Among 15 cases, ten $(\# 2,3,5,6,9,11-15)$ were untreated and the remaining five (\#1, 4, $7,8,10)$ were previously treated by an incomplete transsphenoidal adenomectomy. The adrenal and thyroid functions were normal in all cases. These patients received bromocriptine (Sandoz, Basel ; $10-20 \mathrm{mg} /$ day, every $6 \mathrm{hrs}$ ) for 2 to 21 months, and subsequently combined administration of bromocriptine and cyproheptadine (Banyu, Tokyo; $12-16 \mathrm{mg} /$ day, every $6 \mathrm{hrs}$ ) for 8 to 52 months (Table 1). Blood sampling during the treatment was done 3 to 6 hours after the drug ingestion.

Before and during the treatment, TRH (Tanabe, Osaka ; $500 \mu \mathrm{g}$, iv) and GHRH [GHRH (1-44) $\mathrm{NH}_{2}$, Sumitomo, Osaka; $100 \mu \mathrm{g}$, iv] tests were performed according to the methods previously reported (Hanew et al., $1980 ; 1988$ ), and blood samples were obtained at $-30,0 \mathrm{~min}$ before and $15,30,45,60,90,120 \mathrm{~min}$ after the injection of each agent.

Plasma GH, prolactin (PRL), and somatomedin-C (Sm-C) were measured with commercial RIA kits (GH, Dainabot, Tokyo; PRL, Sorin, Gif-sur-Yvett ; Sm-C, Nichols Institute, San Juan Capistrano, CA) and the minimal detectable

Table 1. Clinical and laboratory data in 15 patients with acromegaly

\begin{tabular}{|c|c|c|c|c|c|c|c|c|c|}
\hline \multirow{2}{*}{ Subjects } & \multirow{2}{*}{ Sex } & \multirow{2}{*}{ Age } & \multirow{2}{*}{$\begin{array}{l}\text { Plasma } \mathrm{GH}^{\mathrm{a}} \\
\text { (ng/ml) }\end{array}$} & \multirow{2}{*}{$\begin{array}{l}\text { Plasma } \mathrm{PRL}^{\mathrm{b}} \\
(\mathrm{ng} / \mathrm{ml})\end{array}$} & \multicolumn{2}{|c|}{ Bromocriptine } & \multicolumn{2}{|c|}{ Cyproheptadine ${ }^{\mathrm{c}}$} & \multirow{2}{*}{$\begin{array}{l}\text { Previous } \\
\text { therapy }^{\mathrm{d}}\end{array}$} \\
\hline & & & & & $\begin{array}{l}\text { dose } \\
(\mathrm{mg})\end{array}$ & $\begin{array}{l}\text { duration } \\
\text { (M) }\end{array}$ & $\begin{array}{l}\text { dose } \\
(\mathrm{mg})\end{array}$ & $\begin{array}{l}\text { duration } \\
\text { (M) }\end{array}$ & \\
\hline 1 & $\mathrm{~F}$ & 32 & 8.7 & 11.5 & 10 & 10 & 12 & 18 & TS \\
\hline 2 & $\mathrm{~F}$ & 73 & 10.2 & 10.1 & 10 & 6 & 16 & 10 & None \\
\hline 3 & $\mathrm{~F}$ & 58 & 10.3 & 28.6 & 10 & 21 & 12 & 12 & None \\
\hline 4 & $F$ & 37 & 11.9 & 11.3 & 10 & 10 & 16 & 15 & $\mathrm{TS}$ \\
\hline 5 & M & 55 & 12.2 & 5.5 & 10 & 4 & 16 & 11 & None \\
\hline 6 & M & 57 & 17.1 & 5.0 & 10 & 16 & 16 & 18 & None \\
\hline 7 & M & 26 & 17.5 & 12.0 & 10 & 4 & 16 & 12 & TS \\
\hline 8 & M & 23 & 28.6 & 9.2 & 10 & 2 & 16 & 27 & TS \\
\hline 9 & M & 58 & 35.0 & 6.0 & 20 & 7 & 16 & 37 & None \\
\hline 10 & $\mathrm{~F}$ & 25 & 37.0 & 11.7 & 20 & 2 & 16 & 37 & TS \\
\hline 11 & $\mathbf{M}$ & 36 & 43.8 & 5.6 & 10 & 2 & 16 & 12 & None \\
\hline 12 & $\mathrm{~F}$ & 62 & 46.3 & 14.3 & 10 & 4 & 16 & 52 & None \\
\hline 13 & $F$ & 72 & 54.0 & 13.1 & 10 & 10 & 16 & 8 & None \\
\hline 14 & M & 33 & 63.3 & 5.2 & 20 & 4 & 16 & 16 & None \\
\hline 15 & $\mathbf{M}$ & 43 & 73.4 & 6.3 & 10 & 12 & 16 & 37 & None \\
\hline
\end{tabular}

a, b: Mean value for seveal basal samples. c: Cyproheptadine was administered with bromocriptine. d: TS, Transsphenoidal pituitary adenomectomy. 
levels were $0.2 \mu \mathrm{g} / \mathrm{L}, 1 \mu \mathrm{g} / \mathrm{L}$, and $0.1 \mathrm{U} / \mathrm{ml}$, respectively (Hanew et al., $1980 ; 1988$ ).

The pituitary CT-scan was examined before and during the combination therapy of bromocriptine and cyproheptadine. Student's $t$-test was used after $\log$ transformation of each datum, if necessary, for statistical evaluations.

\section{Results}

1) Plasma $\mathrm{GH}$ levels in 15 acromegalic patients before and during treatment with bromocriptine alone or combined treatment with bromocriptine and cyproheptadine.

Following bromocriptine treatment, 6 of 15 cases $(40 \%)$ showed plasma GH decrease over $50 \%$ from the pretreatment values, although each value was still higher than the normal ranges $(6.3-60.5 \mu \mathrm{g} / \mathrm{L})$ (Fig. la).

When cyproheptadine was added, plasma $\mathrm{GH}$ decreased further and 11 cases (73\%) showed a decrease of more than $50 \%$ from the pretreatment values and normalization of plasma $\mathrm{GH}$ was obtained in 8 cases (\#1-3, 5, 8, 10, 11, 13) (Fig. 1a).

In 15 patients, the mean plasma $\mathrm{GH}$ value for the combined bromocriptine and cyproheptadine therapy $(9.4 \pm 3.0 \mu \mathrm{g} / \mathrm{L})$ was significantly lower than either that of the single bromocriptine therapy $(19.0 \pm 3.9 \mu \mathrm{g} / \mathrm{L}$; $\mathrm{P}<0.005)$ or the pretreatment value $(31.3 \pm$ $5.5 \mu \mathrm{g} / \mathrm{L}, \mathrm{P}<0.001$ ) (Fig. 1b). In all 8 patients, who showed $\mathrm{GH}$ normalization during the combined treatment, the plasma
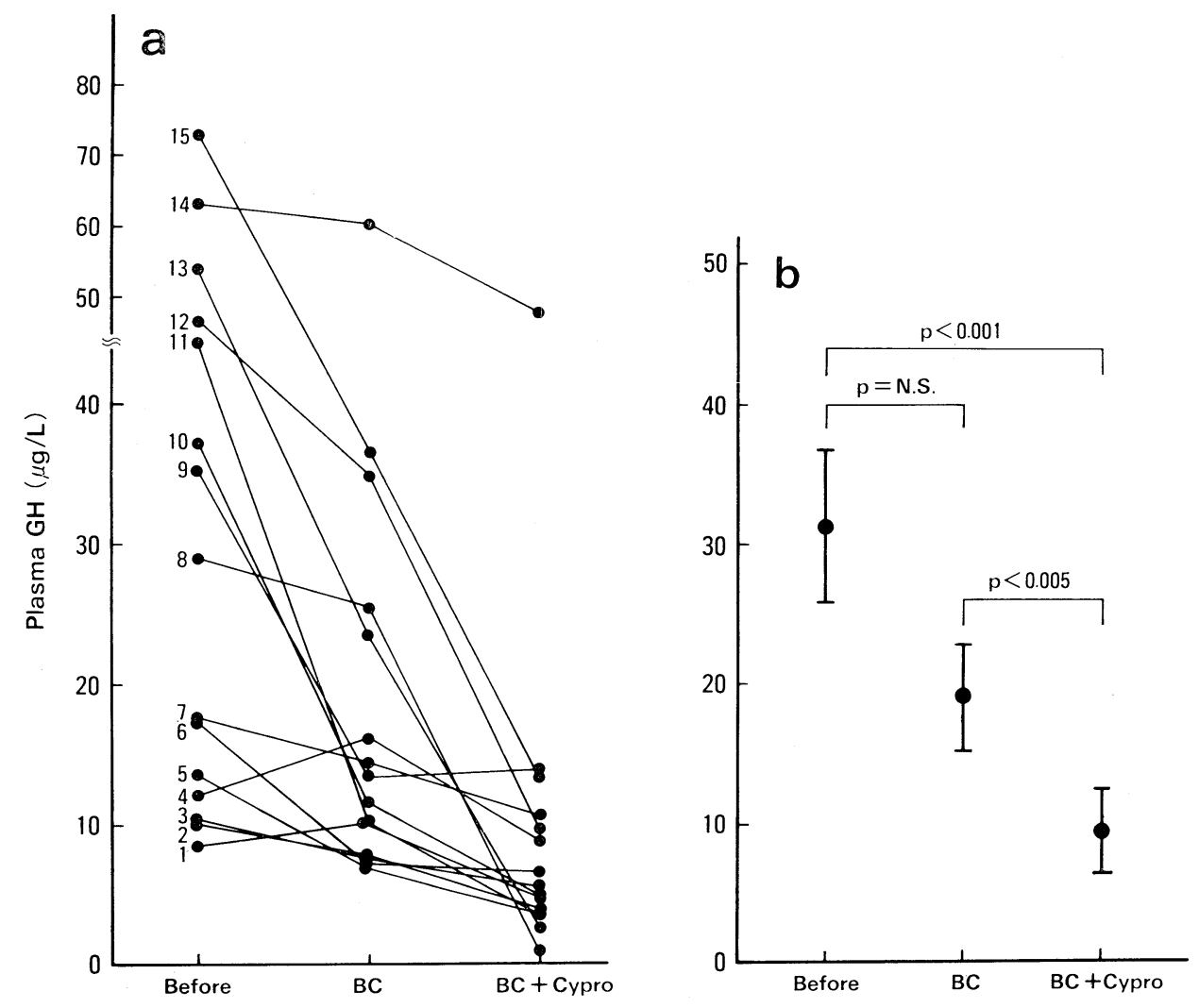

Fig. 1. Plasma GH levels in 15 acromegalic patients before and during the medical treatment. a, individual value : $b$, mean \pm SEM of these values. $B C:$ bromocriptine, Cypro : cyproheptadine 
Sm-C level during the treatment was within the normal ranges $(0.3-1.8 \mathrm{U} / \mathrm{ml}$; Mean, $1.2 \pm 0.2 \mathrm{U} / \mathrm{ml}$; normal range $0.7-2.0 \mathrm{Um} /$ ml) (Table 2).

Cyproheptadine administration was discontinued in two patients $(\# 1 \& 5)$. Their plasma $\mathrm{GH}$ rose to the level of the single
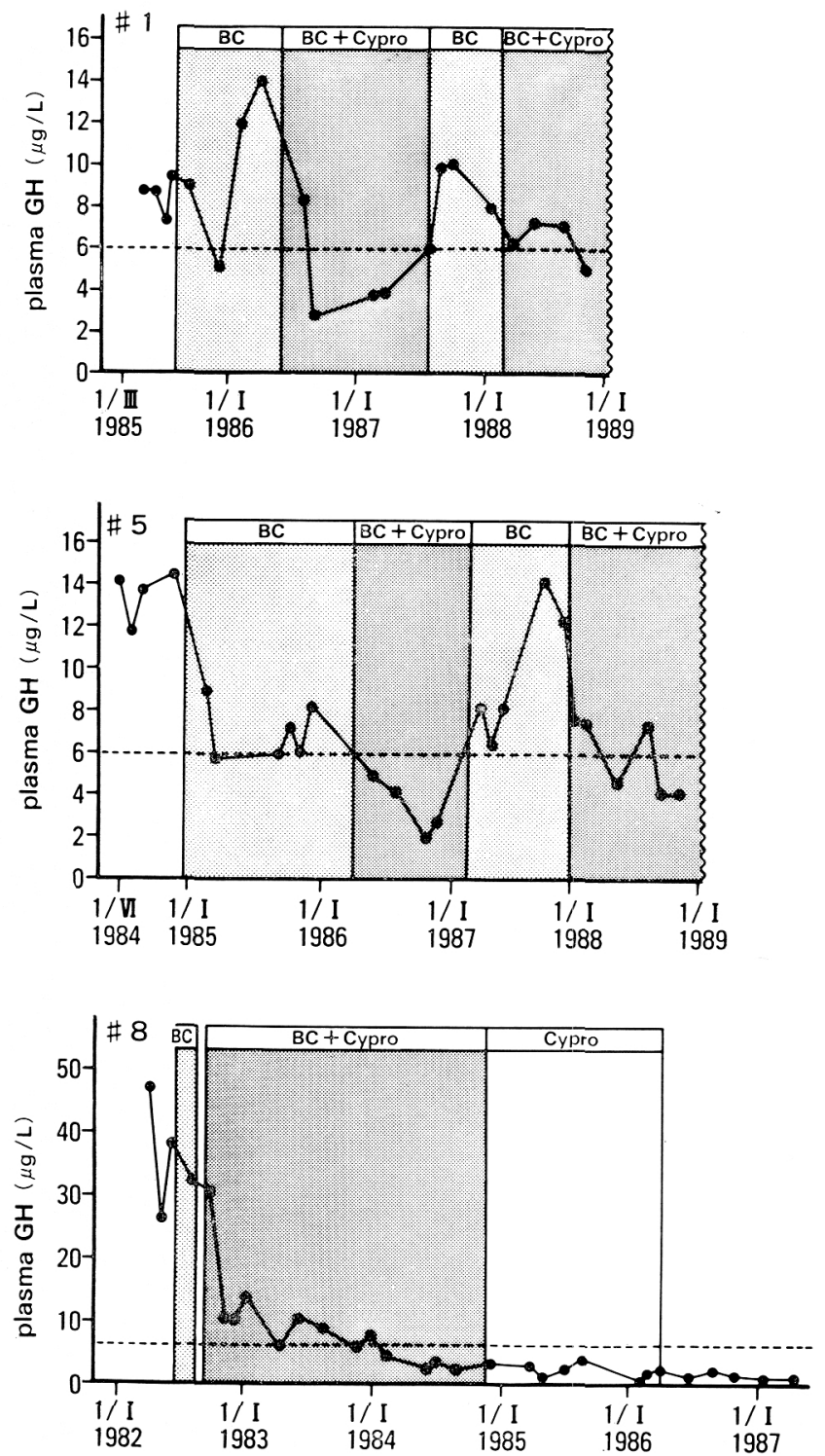

Fig. 2. Plasma GH profile in three patients $(\# 1,5,8)$ before and during the bromocriptine and/or cyproheptadine therapy. bromocriptine therapy, and fell again after the recommencement of cyproheptadine administration (Fig. 2). Plasma GH levels in one patient $(\$ 8)$ remained in the low normal ranges and the response to TRH disappeared (data not shown) even after the cessation of both agents, and this patient was considered to be cured completely (Fig. 2).

The levels of plasma PRL during the single bromocriptine treatment $(3.9 \pm 0.4 \mu \mathrm{g} / \mathrm{L})$ and the combined treatment $(2.8 \pm 0.3 \mu \mathrm{g} / \mathrm{L})$ were significantly lower than the pretreatment level $(10.4 \pm 1.5 \mu \mathrm{g} / \mathrm{L})$ (both $\mathrm{P}<0.001$ ), and the value during the combined treatment was also slightly lower than for single bromocriptine treatment $(\mathrm{P}<0.05)$ (individual data not shown).

2) Plasma GH responses to TRH and GHRH in acromegalic patients before and during the single bromocriptine and the combined bromocriptine and cyproheptadine treatment.

Six of 15 patients received TRH (\#3, 5, 6, 8, 11, 12) and GHRH tests $(\# 2,3,5,6,11,12)$ before and during the treatments. All patiens except two (\#6,12) were the cases who showed GH normalization in response to the combination therapy (see Fig. 1a). After TRH injection, plasma $\mathrm{GH}$ increased markedly (peak $=15 \mathrm{~min}$, $322.2 \pm 100.7 \mu \mathrm{g} / \mathrm{L}$ ) before treatment, and the response was blunted modestly during the single bromocriptine treatment (peak $=15 \mathrm{~min}$, $161.2 \pm 63.6 \mu \mathrm{g} / \mathrm{L} ; \quad \mathrm{P}=\mathrm{NS}$ ) (Fig. 3a). After the addition of cyproheptadine, the GH response was further-suppressed (pretreatment vs combined treatment, $15 \mathrm{~min}, 322.2$ \pm 100.7 vs $48.6 \pm 18.3, \quad \mathrm{P}<0.02$; 
Table 2. Plasma $\mathrm{Sm}-\mathrm{C}$ values $(\mathrm{U} / \mathrm{ml})$ before and during the bromocriptine (BC) and cyproheptadine (Cypro) therapy in $8 \mathrm{GH}$ normalized patients with combination therapy

\begin{tabular}{cccc}
\hline \hline Subjects & Before & BC & BC+Cypro \\
\hline 1 & 3.9 & 2.8 & 1.8 \\
2 & 3.0 & 1.6 & 1.2 \\
3 & 2.2 & 2.2 & 1.4 \\
5 & 2.8 & 2.7 & 0.9 \\
8 & - & - & 0.3 \\
10 & - & - & 1.2 \\
11 & 2.7 & 2.1 & 1.2 \\
13 & 3.4 & - & 1.4 \\
\hline
\end{tabular}

$30 \mathrm{~min}, \quad 316.8 \pm 126.1$ vs $47.5 \pm 21.2, \mathrm{P}<$ $0.05 ; 60 \mathrm{~min}, 173.0 \pm 77.6$ vs $32.3 \pm 18.8 \mu \mathrm{g} /$ $\mathrm{L}, \mathrm{P}<0.05$ ) (Fig. 3a).

Plasma GH response to GHRH was also slightly suppressed by the single bromocriptine therapy compared to the pretreatment response $(\mathrm{P}=\mathrm{NS})$. The response was marked- ly suppressed by the addition of cyproheptadine (pretreatment vs combined treatment: $15 \mathrm{~min}, 62.4 \pm 24.0$ vs $15.5 \pm 7.1 ; 30$ $\min , 59.1 \pm 20.7$ vs $16.6 \pm 7.0 ; 45 \mathrm{~min}, 61.1$ \pm 17.8 vs $17.7 \pm 6.5 ; 60 \mathrm{~min}, \quad 59.2 \pm 15.4$ vs $18.4 \pm 6.0 ; 90 \mathrm{~min}, 53.5 \pm 12.8$ vs $16.1 \pm$ $3.8 ; 120 \mathrm{~min}, 47.9 \pm 14.5$ vs $15.4 \pm 3.6 \mu \mathrm{g} / \mathrm{L}$, all $\mathrm{P}<0.05$ ) (Fig. 3b).

3) Pituitary adenoma size before and during the bromocriptine and cyproheptadine therapy in previously untreated acromegalic patients.

Seven acromegalic patients, who were previously untreated, received a pituitary CT-scan before treatment and during the bromocriptine and cyproheptadine treatment. The CT-scan during the combination therapy was performed 8 to 44 months after the start of the therapy. Four of seven patients showed a reduction in the tumor size (maximal height) exceeding the
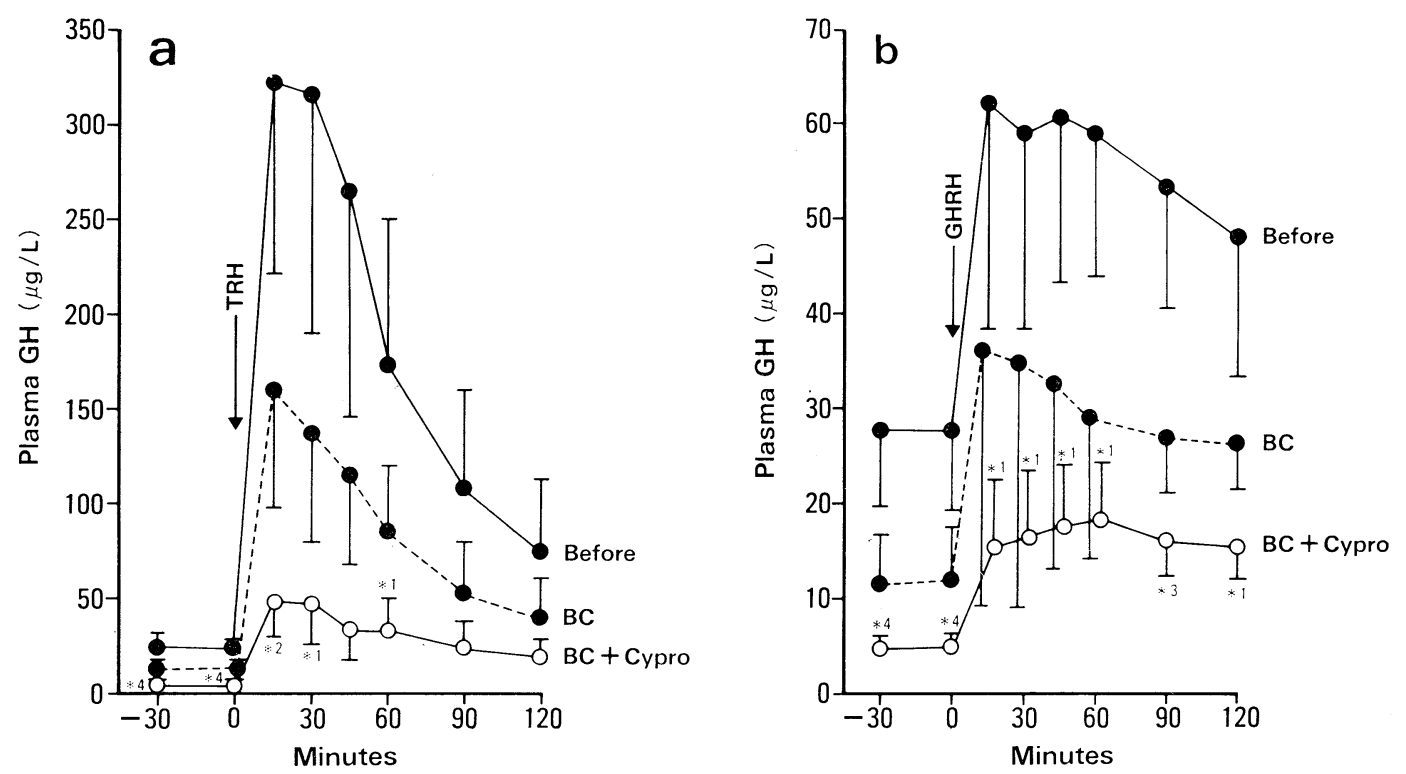

Fig. 3. Plasma GH responses to TRH (a) and GHRH (b) in 6 acromegalic patients before and during the single bromocriptine $(\mathrm{BC})$ or the combined bromocriptine and cyproheptadine treatment $(\mathrm{BC}+$ Cypro). vs pretreatment: $* 1, \mathrm{P}<0.05 ; * 2, \mathrm{P}<0.02 ; * 3, \mathrm{P}<0.01 ; * 4, \mathrm{P}<$ 0.005 
Patient 13
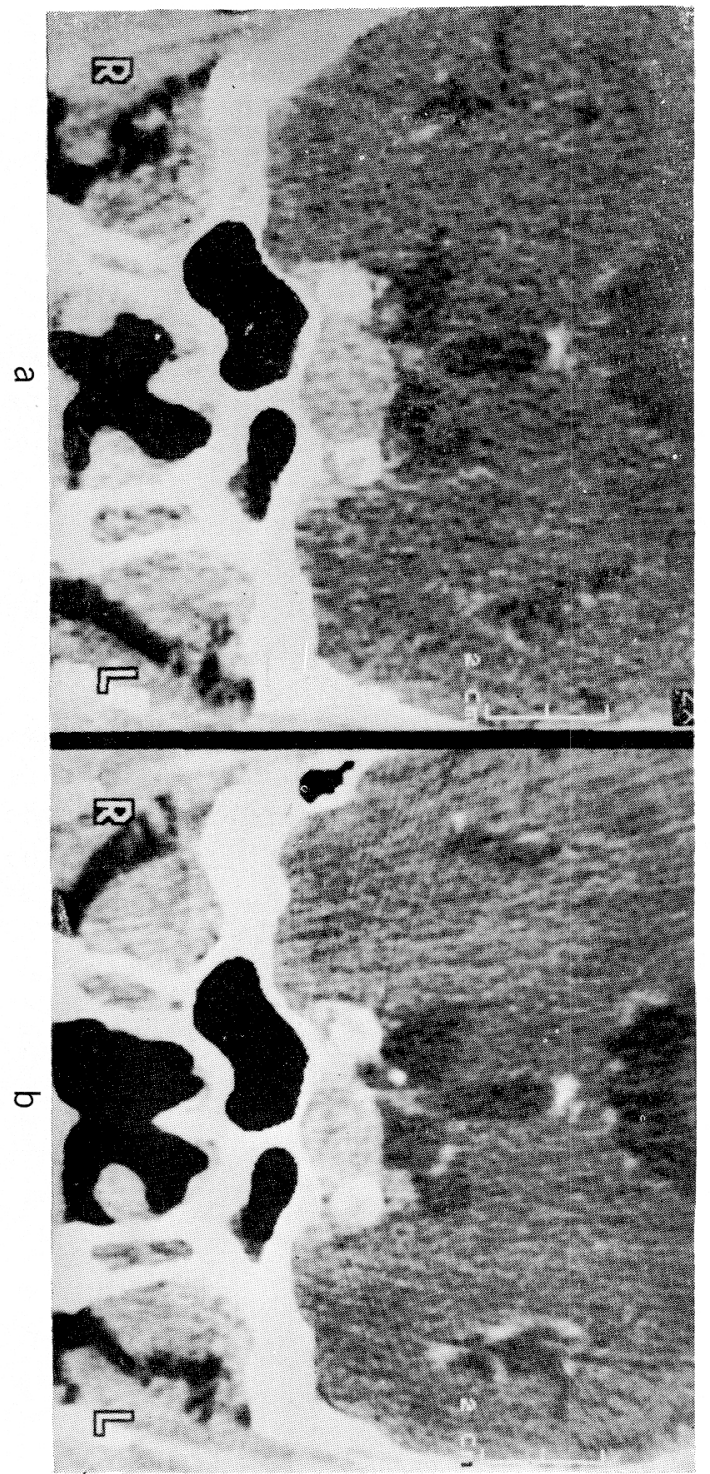

Patient 11
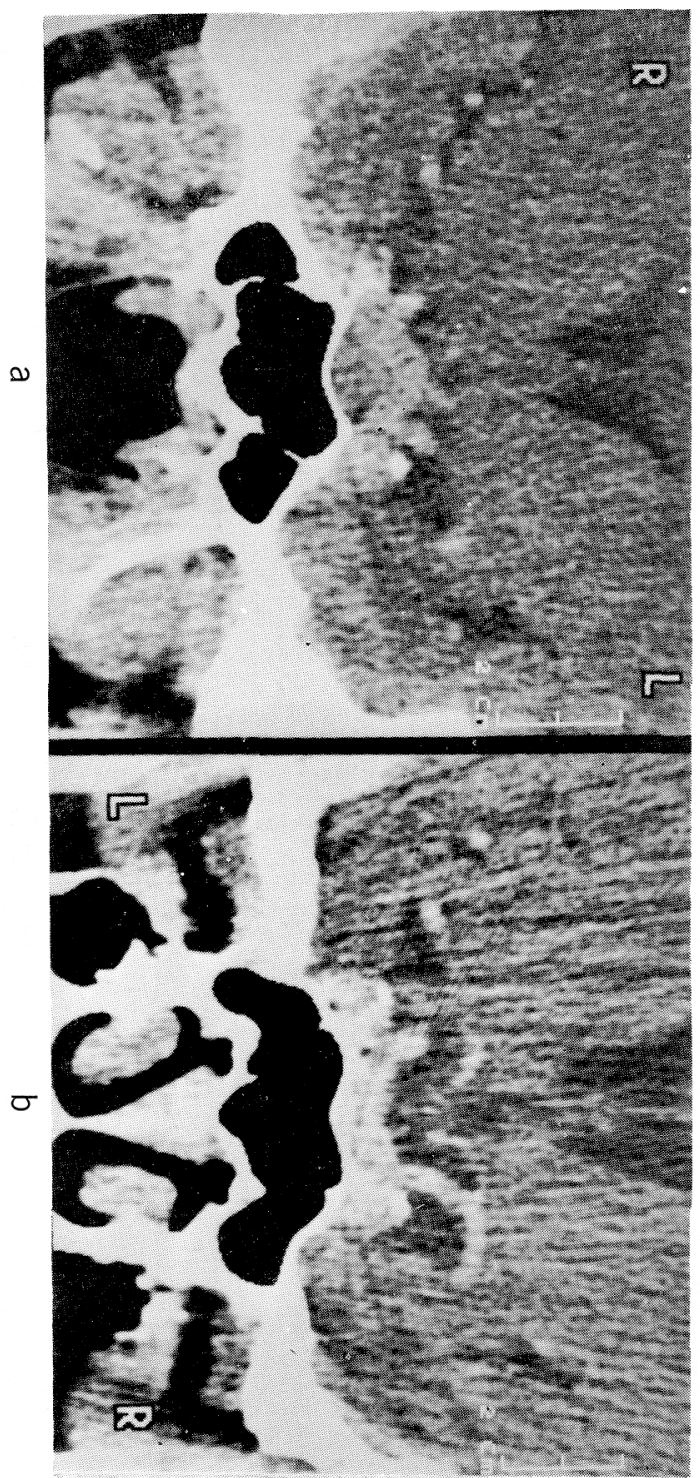

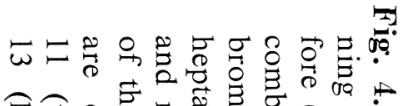

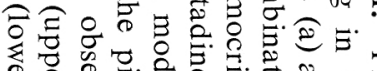

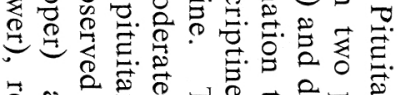

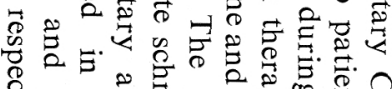

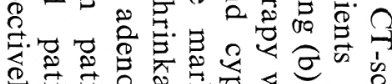

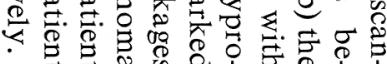


CT slice width (1.5-3 mm) (Table 3). CT changes in most representative cases $(\# 11$, 13) are shown in Fig. 4.

Table 3. Adenoma size before and during the bromocriptine and cyproheptadine therapy in previously untreated acromegalic patients

\begin{tabular}{cccc}
\hline \hline \multirow{2}{*}{ Subjects } & \multicolumn{3}{c}{ Adenoma Size $(\mathrm{mm})^{\mathrm{a}}$} \\
\cline { 2 - 4 } & Before & \multicolumn{2}{c}{ During $($ months) } \\
\hline 3 & 12.3 & 9.9 & $(8)$ \\
5 & 7.0 & 2.5 & $(24)$ \\
9 & 15.3 & 15.3 & $(41)$ \\
11 & 16.5 & 11.2 & $(16)$ \\
12 & 14.1 & 13.3 & $(44)$ \\
13 & 16.7 & 11.8 & $(9)$ \\
14 & 16.8 & 16.7 & $(13)$ \\
\hline
\end{tabular}

a : Maximal height of the adenoma.

$\mathrm{b}$ : Duration of the combination therapy.

\section{Discussion}

In this study, eight out of 15 acromegalic patients, in whom GH normalization was not achieved with bromocriptine therapy alone, showed GH normalization after the combination therapy with bromocriptine and cyproheptadine. Plasma $\mathrm{GH}$ responses to TRH or GHRH were also significantly inhibited in these patients, and a clear reduction in the tumor size was observed in 4 of 7 patients, whereas consistent results have not yet been obtained regarding the effect of single bromocriptine therapy on tumor size in acromegalic patients (Faglia et al., 1985, Besser and Wass, 1987).

Although bromocriptine is known to inhibit GH secretion in acromegalic patients by its direct action on the pituitary adenoma (Molinatti et al., 1984), the possibility of simultaneous GH stimulation via the hypothalamus has been proposed by us (Hanew et al., 1987) and Camanni et al. (1977). Cyproheptadine is reported to inhibit sleep-induced $\mathrm{GH}$ secretion and $\mathrm{GH}$ responses to several exogenous stimuli, which probably mediate the stimulation of hypothalamic GHRH or the inhibition of hypothalamic somatostatin release in normal subjects (Bivens et al., 1973; Nakai et al., 1975; Smyth et al., 1974; Nakai et al., 1975 ; Chihara et al., 1976 ; Dammacco et al., 1977; Hainer et al., 1981; Alba-Roth et al., 1988). Cyproheptadine has antiserotonergic, anti-histaminergic and weak anti-cholinergic actions (Williams and Martin, 1982). The GH inhibitory action of the cyproheptadine might be due to the antiserotonergic action, since 5HTP (5-hydroxytryptophan: the precursor of serotonin)induced GH release is inhibited by pretreatment with cyproheptadine (Nakai et al., 1974), This action might take place at the level of the hypothalamus. However, because plasma GH response to TRH and GHRH was significantly blunted and pituitary tumor size was clearly reduced in 4 of 7 patients during the bromocriptine and cyproheptadine combination therapy, cyproheptadine might have a direct suppressive effect on pituitary adenomas.

Concerning this, Ishibashi et al., (1985) have reported that cyproheptadine inhibited $\mathrm{GH}$ secretion from $\mathrm{GH}$ secreting tumors in vitro, probably through a non-serotonergic mechanism. In addition to such direct suppressive effects, we should consider the possibility that functional and morphological changes were caused by a chronic suppression of GHRH and/or chronic stimulation of somatostatin secretion from the hypothalamus.

Previous animal experiments revealed no direct effect of serotonin on basal $\mathrm{GH}$ secretion (Kato et al., 1980; Hall, 1982; Hall et al., 1984). With a histochemical technique, synaptic connections between serotonergic nerve endings and somatostatin neurons have been observed in the rat anterior periventricular nucleus (Kiss et al., 1988). Alhough serotonin has been reported to have an inhibitory (Richardson et al., 1981) or no effect (Chihara et al., 1979; Peterfreund and Vale 1983) on basal 
somatostatin secretion from the rat hypothalamus, anti-somatostatin serum does not inhibit 5HTP induced GH release (Kato et al., 1980). In contrast, pretreatment with rabbit anti serum specific for rat GHRH abolishes the plasma $\mathrm{GH}$ increase induced by 5HTP or serotonin in rats (Murakami et al., 1986).

These observations support the theory that cyproheptadine, at least in part, inhibits GH secretion in acromegalic patients via the inhibition of hypothalamic GHRH release. As for the effect of cyproheptadine on acromegalic GH secretion, Kato et al. (1983) observed $\mathrm{GH}$ lowering in 3 of 4 patients and $\mathrm{GH}$ normalization in one patient. However, the inhibitory effect of acute cyproheptadine administration on acromegalic GH secretion is generally weak (Feldman et al., 1976; Chiodini et al., 1976; Kato et al., 1983), and seldom is the normalization of $\mathrm{GH}$ obtained with single cyproheptadine treatment (Faglia et al., 1985; Kato et al., 1983). We also could not find any acute GH suppressive effect of cyproheptadine in several acromegalic patients (unpublished data), and we did not try single cyproheptadine therapy. The effectiveness of the bromocriptine and cyproheptadine combination therapy seems to indicate that cyproheptadine might have an inhibitory effect on GHRH secretion if bromocriptine has dual actions on acromegalic GH secretory tumors; i. e. one is a directly suppressive effect and the other an indirect stimulatory effect via the hypothalamus (Camanni et al., 1977 ; Hanew et al., 1987).

With the combination therapy, we observed untoward effects in only one patient (\#10), who complained of increased appetite and body weight.

Four of 15 patients ( $\# 2,7,9,14)$ previously received treatment with somatostatin analogue (SMS 201-995, $200 \mu \mathrm{g} / \mathrm{day}$ bidtid) for 3 to 8 weeks, and $\mathrm{GH}$ and $\mathrm{Sm}-\mathrm{C}$ levels were normalized in 3 patients $(\# 2$, 7, 9). However, these patients complained of pain in the injection site, epigastral discomfort, anorexia, urinary irritation, troublesomeness of injection, and they preferred oral medication to SMS therapy.

In conclusion, we have observed clear GH suppression following the bromocriptine and cyproheptadine combination therapy in patients with acromegaly who did not show GH normalization when on single bromocriptine therapy. Such a combination therapy is recommended for acromegalic patients who have received incomplete pituitary adenomectomy, refused surgery or SMS therapy, and patients showing inadequate $\mathrm{GH}$ suppression in response to treatment with bromocriptine alone.

\section{Acknowledgements}

We thank Miss T. Kato, Miss S. Takahashi and Miss Y. Shikoda for their excellent technical and secretarial assistance. This work was partly supported by a Research Grant from the Intractable Disease Division, Public Health Bureau, Ministry of Health and Walfare, Japan.

\section{References}

Alba-Roth, J., O. A. Muller, J. Schopohl and K. von Werder (1988). Arginine stimulate growth hormone secretion by suppressing endogenous somatostatin secretion. J. Clin. Endocrinol. Metab. 67, 1186-1189.

Besser, G. M. and Wass, J. A. H. The use of dopamine agonists in the management of acromegaly. In : Robbins, RJ, Melmed, S, eds. Acromegaly: A century of scientific and clinical progress. Plenum Press, New York, p. 261-266 (1987).

Bivens, C. H., H. E. Lebovitz and J. M. Feldman (1973). Inhibition of hypoglycemia-induced growth hormone secretion by the serotonin antagonist cyproheptadine and methysergide. New Engl. J. Med. 289, 236-239.

Camanni, F., F. Massara, L. Belforte, A., Rosatello and G. M. Molinatti (1977). Effect of dopamine on plasma growth hormone and prolactin levels in normal and acromegalic 
subjects. J. Clin. Endocrinol. Metab. 44, 465473.

Chihara, K., Y. Kato, K. Maeda, S. Matsukura and H. Imura (1976). Suppression by cyproheptadine of human growth hormone and cortisol secretion during sleep. J. Clin. Invest. 57, 1393-1402.

Chihara, K., A. Arimura and A.V. Schally (1979). Effect of intraventricular in jection of dopamine, norepinephrine, acetylcholine and 5-hydroxytryptamine on immunoreactive somatostatin release into rat hypophysial portal blood. Endocrinology 104, 1656-1662.

Chiodini, P. G., A. Liuzzi, E. E. Muller, L. Botalla, G. Cremascoli, G. Oppigi, A. Verde and F. Silvestrini (1976). Inhibitory effects of an ergoline derivative, methergoline, on growth hormone and prolactin levels in acromegalic patients. J. Clin. Endocrinol. Metab. 43, 356-363.

Dammacco, F., F. M. Puca, N. Riillo, S. Genco, L. M. Specchio, G. Chertri, C. Torelli, C. Mastrangelo, C. Candeliere and D. Galeone (1977). Inhibitory effect of cyproheptadine administration on the sleep-related growth hormone secretion in man. Horm. Metab. Res. 9, 244-245.

Daughaday, W. H. The Anterior Pituitary. In : Wilson JD, Foster DN, eds. Textbook of Endocrinology. W. B. Saunders, Philadelphia, p 568-613 (1985).

Faglia, G., M. Arosio and B. Ambrosi Recent advances in diagnosis and treatment of acromegaly. In : Imura H. eds. Pituitary Gland. Raven Press, New York, p 363-404 (1985).

Feldman, J. M., J. W. Plonk and C. H. Bivens (1976). Inhibitory effect of serotonin antagonists on growth hormone release in acromegalic patients. Clin. Endocrinol. 5, 71-78.

Frohman, L. A. Disease of the Anterior Pituitary. In: Felig p, Baxter JD, Broadus AE, Frohman LA eds. Endocrinology and Metabolism. McGraw-Hill, New York, p 247337 (1987).

Hainer, V., J. Urbanek, B. Malec and L. Krejcik (1981). The effect of TRH, cyproheptadine and pimozide on the growth hormone response to intramuscular glucagon. Horm. Metab. Res. 13, 451-453.

Hall, T. R. (1982). Neurotransmitter effects on release of prolactin and growth hormone in vitro from pituitary glands of the pigeon, columbia livia. J. Endocrinol. 92, 303-308.
Hall, T. R., S. Harvey and A. Chadwick (1984). Serotonin and acetylcholine affect the release of prolactin and growth hormone from pituitary glands of domestic fowl in vitro in the presence of hypothalamic tissue. Acta Endocrinol. 105, 455-462.

Hanew, K., M. Kokubun, A. Sasaki, T. Mouri, and K. Yoshinaga (1980). The spectrum of pituitary growth hormone responses to pharmacological stimuli in acromegaly. J. Clin. Endocrinol. Metab. 51, 292-297.

Hanew, K., A. Sasaki, S. Sato, M. Goh and K. Yoshinaga (1987). Growth hormone inhibitory and stimulatory actions of L-dopa in patients with acromegaly. J. Clin. Endocrinol. Metab. 64, 255-260.

Hanew, K., M. Goh, S. Sato. Y. Shimizu, A. Sasaki, M. Aida and K. Yoshinaga (1988). The effect of acute and chronic growth hormone $(\mathrm{GH})$ administration on $\mathrm{GH}$ secretion in patients with idiopathic GH deficiency. $J$. Clin. Endocrinol. Metab. 66, 715-721.

Ishibashi, M., T. Fukushima and T. Yamazi (1985). Cyproheptadine-mediated inhibition of growth hormone and prolactin release from pituitary adenoma cells of acromegaly and gigantism in culture. Acta Endocrinol. 109, 474-480.

Kato, Y., N. Matsushita, H. Katakami and H. Imura (1980). Brain serotonin and the secretion of prolactin and growth hormone. Clin. Endocrinol. (Tokyo) 28, 627-632.

Kato, Y., Y. Kabayama and H. Ohta (1983). Effective long term treatment with cyproheptadine of patients with acromegaly. The 65th Annual Meeting of American Endocrine Society, Abst. \#197.

Kiss, J., A. Csaky and B. Halasz (1988). Demonstration of serotonergic axon terminals on somatostatin-immunoreactive neurons of the anterior periventricular nucleus of the rat hypothalamus. Brain Res. 442, 23-32.

Molinatti, G. M., F. Cammanni, F. Massara, E. Ghigo and E. Ciccarelli. Neuropharmacologic control of GH, PRL, and TSH secretion in acromegaly and some hyperprolactinemic conditions. In : Camanni F, Muller EE eds. Pituitary Hyperfunction: Physiology and Clinical Aspects. Raven Press, New York, p 193-207 (1984).

Murakami, Y., Y. Kato, Y. Kabayama, K. Tojo, T. Inose and H. Imura (1986). Involvement of growth hormone $(\mathrm{GH})$-releasing factor in 
GH secretion induced by serotonergic mechanism in conscious rats. Endoclinology 119, 1089-1092.

Nakai, Y., H. Imura, H. Sakurai, H. Kurahachi and T. Yoshimi (1974). Effect of cyproheptadine on human growth hormone secretion. J. Clin. Endocrinol. Metab. 38, 446-449.

Nakai Y. and H. Imura (1975). Suppressive effect of cyproheptadine on L-dopa-induced growth hormone release in man. Endocrinol. Japon. 22, 357-360.

Peterfreund, R. A. and W. W. Vale (1983). Muscarinic cholinergic stimulation of somatostatin secretion from long term dispersed cell cultures of fetal rat hypothalamus: In- hibition by $\gamma$-aminobutyric acid and serotonin. Endocrinology 112, 526-534.

Richardson, S. B., C. S. Hollander, J. A. Prasad and Y. Hirooka (1981). Somatostatin release from rat hypothalamus in vitro: effects of melatonin and serotonin. Endocrinology 109, 602-606.

Smythe, G. A. and L. Lazarus (1974). Suppression of human growth hormone secretion by melatonin and cyproheptadine. J. Clin. Invest. 54, 116-120.

Williams, M. and G. E. Martin (1982). Selectivity of cyproheptadine as assessed by radioligand binding. J. Pharm. Pharmacology 34, 58-59. 